\title{
The potential of immunological tests as tools in the epidemiology of leprosy
}

\author{
G KRONVALL \\ Department of Medical Microbiology, Sölvegatan 23, Lund, \\ S-22362 Sweden
}

The immune recognition of the invading organisms by the host has been utilized for diagnostic purposes since the early days of clinical microbiology. The Widal test in cases of typhoid fever can be mentioned as one example. An in vivo test of considerable significance was the tuberculin test, a byproduct from early attempts at vaccination against tuberculosis. Bacteria and other microorganisms which enter the human body, either aided by their virulence factors or by defects in the normal barriers of the host, trigger the production of soluble antibodies or sensitized lymphocytes with binding sites specific for the microbe. Measurements of these responses were particularly helpful in cases where the causative organism was difficult to recover because of special growth requirements or localization of the infection to inaccessible sites. Over the years the continuous development of new immunological techniques has been followed by a parallel development of applications in studies of infectious diseases. In leprosy these developments were severely hampered by lack of antigen from the causative organism, Mycobacterium leprae, which cannot be grown on artificial media. The only test for many years was the in vivo lepromin reaction introduced by Mitsuda in 1919. Recent progress in the zultivation of $M$. leprae in armadillos has dramatically changed the picture. The whole array of immunological tests can now be applied to studies of leprosy with antigen available from in vivo grown leprosy bacilli. It is therefore pertinent to look at the performance of these tests and their possible use in epidemiology and clinical work.

Potential use of immunological tests

The immune response to a microorganism is multi-faceted with qualitative and quantitative variations regarding immunoglobulin classes and subclasses, cell types and subtypes, and bacterial antigens involved. It follows that measurements of immunity might reflect various aspects of the host-parasite relationship, such as protective immunity, toxin neutralization, hostdestructive immune reactions as well as quite 
irrelevant responses with no functions either way. Unlike direct tests for the identification of the causative agent which are limited to the actual time of infection, immunological tests might also give an account of previous events even if they have not shown up as overt disease. With these aspects in mind it might be possible to define certain situations where immunological tests might be of value in leprosy research for measurements of:

1. Exposure to M. leprae, subclinical infection

2. Diagnosis of leprosy, classification

3. Degree of protective immunity

4. Degree of host-destructive immunity

5. Identification of high risk individuals

6. Prognosis

A number of immunological techniques are currently available for the determination of humoral or cellular immunity to microbial antigens. Methods relevant to mycobacterial diseases include:

A. TESTS FOR HUMORAL IMMUNE RESPONSES

1. Bacterial agglutination

2. Agglutination of particles coated with antigen

3. Complement fixation tests

4. Precipitation methods in gel or in solution

5. Radioimmunoassays

6. Enzyme-linked immunoassays

B. TESTS FOR CELLULAR IMMUNE RESPONSES

1. In vivo skin testing

2. Lymphocyte transformation test

3. Leukocyte migration inhibition

4. Antigen binding tests

The performance of the various tests offered must be defined in strict terms in order to make an evaluation and comparison with other tests possible. The two parameters SENSITIVITY and SPECIFICITY are such terms and are defined as per cent positive patients among all patients, and per cent negative among all non-patients, respectively (1). From these figures and knowing the prevalence of disease or of a particular patient group in a given population the predictive values for the test results can be calculated. The predictive value for a positive result (PV pos) is calculated as per cent positive patients among all positive individuals. The predictive value for a negative result (PV neg) is calculated as per cent negative non-diseased individuals among all negative. These values indicate the potential 
use of the test under the given circumstances and are influenced by the sensitivity and specificity values to varying degrees.

Table 1. Effect of sensitivity on predictive values

\begin{tabular}{ccccc}
\hline $\begin{array}{c}\text { Sensitivity } \\
(\%)\end{array}$ & $\begin{array}{c}\text { Low endemic } \\
\text { PV pos }\end{array}$ & $\begin{array}{c}\text { areas } \\
\text { PV neg }\end{array}$ & $\begin{array}{c}\text { High risk group (50) } \\
\text { PV pos }\end{array}$ & $\begin{array}{c}\text { PV neg } \\
100\end{array}$ \\
\hline & 100 & 100 & 100 & 100 \\
70 & 100 & 100 & 100 & 99.5 \\
50 & 100 & 100 & 100 & 98.4 \\
\hline
\end{tabular}

Specificity set to $100 \%$. Prevalence figures for Low endemic area and High risk group: 1.0 and $50 \mathrm{o} / \mathrm{oo}$ (per thousand), resp.

The sensitivity of a method does not influence the predictive values significantly, neither in a low endemic situation nor in a high risk group of people (e.g. spouses of leprosy patients). In too many instances too much emphasis is placed on a high sensitivity of laboratory test methods.

Table 2. Effect of specificity on predictive values

\begin{tabular}{ccccc}
\hline $\begin{array}{c}\text { Specificity } \\
(8)\end{array}$ & $\begin{array}{c}\text { Low endemic area (1) } \\
\text { PV pos }\end{array}$ & $\begin{array}{c}\text { High risk group } \\
\text { PV pos }\end{array}$ & $\begin{array}{c}\text { PV neg } \\
\text { PV neg }\end{array}$ \\
\hline \\
100 & 100 & 100 & 100 & 100 \\
99.9 & 50 & 100 & 98.1 & 100 \\
99 & 9.1 & 100 & 84 & 100 \\
95 & 2 & 100 & 51.3 & 100 \\
\hline
\end{tabular}

Sensitivity set to 100\%. Prevalence figures for Low endemic area and High risk group: 1.0 and 50 o/oo, resp.

On the other hand, even minor changes in the specificity of a method gives dramatic changes of the predictive values for positive test results, particularly in the low endemic area example. A specificity as high as 99.98 gives a predictive value of only $50 \%$ in such an area as shown in table 2. Table 3 gives the specificity values required at this PV pos level for different prevalence rates. 
Tabel 3. Specificity required for $50 \%$ predictive value for positive test.

Specificity of test

$(8)$
Prevalence rate

(o/oo)

$\begin{array}{lc}99.999 & 0.01 \\ 99.99 & 0.1 \\ 99.9 & 1.0 \\ 98.99 & 10 \\ 97.96 & 20 \\ 94.74 & 50 \\ 88.89 & 100 \\ 75.00 & 200\end{array}$

Sensitivity set to $100 \%$. Predictive value for negative test results $100 \%$.

The performance values of an immunological method will determine the potential use of the test for various purposes. Both as a diagnostic screening tool and in epidemiological studies the specificity has to be very close to $100 \%$ in an unselected population, particularly if the prevalence rate in the area is low. As a diagnostic test and in combination with other independent tests, however, the specificity might be lower in high prevalence groups. This is particularly true if the primary selection of the patient material has increased probability of a positive diagnosis. In epidemiology, however, the high specificity of the immunological tests employed is of paramount importance.

$\underline{\text { Immunological tests in tuberculosis }}$

With test performance aspects in mind, previous developments of immunological methods in the field of tuberculosis will be summarized. An agglutination method was developed by Middlebrook and Dubos (2) using red cells coated with antigen from M. tuberculosis. Patients as well as experimental animals showed positive antibody titers in these tests. However, false negative results in patients and false positives in controls were too frequent to permit any practical use of the test. The Boyden technique, using antigens in the coating process different from those involved in themiddlebrook \& Dubos test, was also tested in tuberculosis serology (3). In combination with purification methods the test could be used for detection of antibodies against different antigens. However, poor sensitivity as well as specificity were still prohibitive. In a later review of various agglutination tests in tuberculosis serology, 32 contempo- 
rary studies showed a mean sensitivity of $65.8 \%$ and a mean specificity of 82.7 \% (4).

Double diffusion methods have been widely used in tuberculosis research. In a summary of seven different studies the sensitivity of the method was found to be $82.7 \%$ and the specificity $86.7 \%$ (4). Antigen preparations used were concentrated culture filtrates of $M$. tuberculosis, strain H37Rv or H37Ra. A combination of the Middlebrook \& Dubos test, kaolin agglutination and a double diffusion test gave a sensitivity of $85 \%$ and a specificity of $94 \%$ (5). A method using direct agglutination of $M$. tuberculosis has been described for the serological diagnosis of tuberculosis (6). The agglutination reaction showed a sensitivity of $83.8 \%$ and a specificity of $94.2 \%$.

Radioimmunological methods were applied early for the detection of antibody responses in tuberculosis patients. A protein antigen with a molecular weight of 9-12000 purified from sonicated M. tuberculosis was used in the Farr-technique (7). The antigen showed partial crossreactivity with BCG and to a lesser extent with M. fortuitum and some other bacteria. A solid phase radioimmunoassay using unheated, concentrated H37Rv antigens has also been described (8). The sensitivity of this method at an optimal discriminating level of $20 \%$ was $87.9 \%$ with a specificity of $88.5 \%$. Using another level for better specificity, $30 \%$, the sensitivity decreased to $68.6 \%$ with a specificity of $98.8 \%$. The figures seem promising in comparison with other tests.

With few exceptions the methods reviewed seem inadequate for a more general use due to their poor performance, particularly in terms of specificity. This might to a large extent be attributed to the lack of purified and species-specific antigen components. The antigenic complexity of mycobacteria is illustrated in fig. 1. Two different methods were used to measure antibodies against $\underline{M}$. tuberculosis. One consisted of a staphylococcal radioimmunoassay (9) with unfractionated M. tuberculosis sonicate as antigen. The test gave a poor discrimination between tuberculosis patients and non-patients, but several patients showed high antibody levels (fig. 1A). The other test employed whole M. tuberculosis bacilli. After incubation with serum, bound antibodies were detected using radiolabelled protein A (fig. 1B). When results with levels above mean +2SD j.n one test were compared with results in the other test on an individual basis there was a lack of correlation indicating a marked antigenic heterogeneity in the responses (fig. 1C) .

Immunological tests used for measuring cell mediated immune responses in tuberculosis cover the whole range from skin testing to various in vitro methods. There is an apparent lack of correlation between different tests for cell mediated immune responses $(10,11)$. The old impression of hypersensitivity as one entity and protective immunity as another seems to have a measurable counterpart. A similar dissociation seems to occur also in leprosy (12). As a whole, methods for measuring cell mediated immunity in tuberculosis show low specificity and the general comments relating to the lack of defined antigens is applicable also in this area. However, the methods 
used have contributed to the general understanding of immune phenomena in tuberculosis.
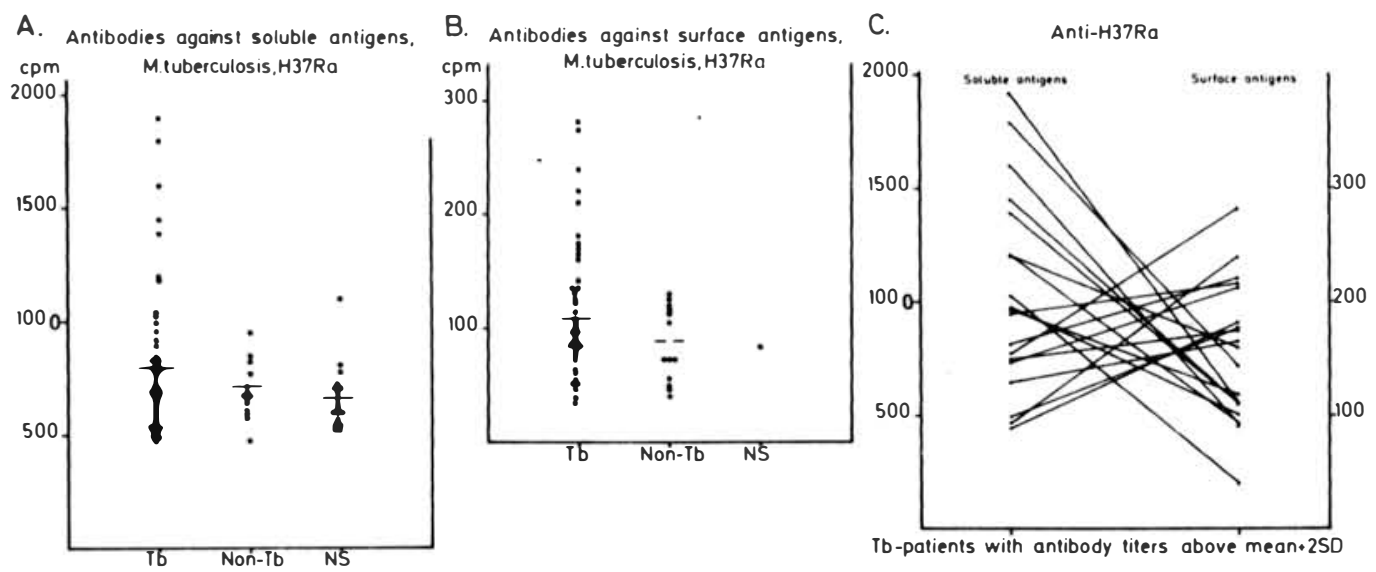

Fig. 1. Tuberculosis patients ( $\mathrm{Tb}$ ), non-tuberculous patients (nonTb), and healthy controls (NS) tested for antibodies against a crude preparation of M. tuberculosis strain H37Ra (Fig. 1A) and surface antigens of $\mathrm{H} 37 \overline{\mathrm{Ra}} \overline{(\mathrm{Fig} \cdot 1 \mathrm{~B}) \text {. Results of the two tests in individual }}$ sera are shown for values above Mean+2SD in one test (Fig. 1C).

Immunological tests in leprosy

Early studies of humoral immune responses in leprosy were restricted by the lack of M. leprae antigen. Mycobacterial antigen preparations from other species were used instead and permitted the detection of antibodies in lepromatous leprosy patients. Double diffusion in gel was a method of choice (13) followed by crossed immunoelectrophoresis $(9,14)$. A sensitive radioimmunoassay against one single antigen component, antigen No. 60 of BCG, increased sensitivity considerably in comparison with previous methods and revealed antibody production also in tuberculoid patients (15). The specificity of the test was low without discrimination between different mycobacterial diseases. Efforts were also made to purify antigen from lepromatous nodules and an M. leprae specific component was described (16). Later extensions of these studies led to the fluorescent leprosy antibody absorption (FLA-ABS) test which shows several interesting features (17). The sensitivity of the test is $100 \%$ in a group of lepromatous patients and 76.5\% among tuberculoid. The specificity as tested in a nonendemic area was 97\%. However, the test does not seem to discriminate between subclinical infection and disease since $91.9 \%$ of household contacts of leprosy patients and 63\% of school children in an endemic area were positive. The method seems promising for certain epidemiological applications. It should be pointed out that anti- 
gens involved in this test are located on the cell surface of the leprosy bacillus.

The availability of $\mathrm{M}$. leprae in larger quantities from inoculated armadillos has boosted immunological studies in leprosy. Analysis of antigen preparations from in vivo grown bacilli showed a very low number of components in contrast to cultivable mycobacteria (18, 19). Hyperimmunization and further concentration of the antigen has revealed some twenty antigens, but most of these are present in very low concentrations (20). A radioimmunological test has been set up for one antigen component, antigen No. 7, which corresponds to the No. 60 antigen of BCG (21). Application of the test to studies of armadillos suggested its use for the detection of early bacillary cases of leprosy.

In order to achieve specificity in an immunological test the choice of antigen used is crucial. Species specific determinants have been detected on one component, the No. 4 antigen of an $M$. leprae reference system $(18,22)$. Crossreacting determinants are present on the corresponding antigen in other mycobacterial species. Studies of these antigens have revealed a closer relationship between $M_{0}$ leprae and $M_{0}$ tuberculosis than between $M_{0}$. leprae and other cultivable bacteria $\overline{(23)}$. The existence of other crossreacting antigens is illustrated in fig. 2. A partially purified preparation of antigen No. 17 from M. smegmatis was radiolabelled and its binding in a staphylococcal $\bar{r}$ adiolmmunoassay with rabbit anti-M. smegmatis antiserum was inhibited by antigen preparations from different mycobacterial species. Varying degrees of inhibition correlate well to species relatedness and suggest species-specific determinants also on this antigen.

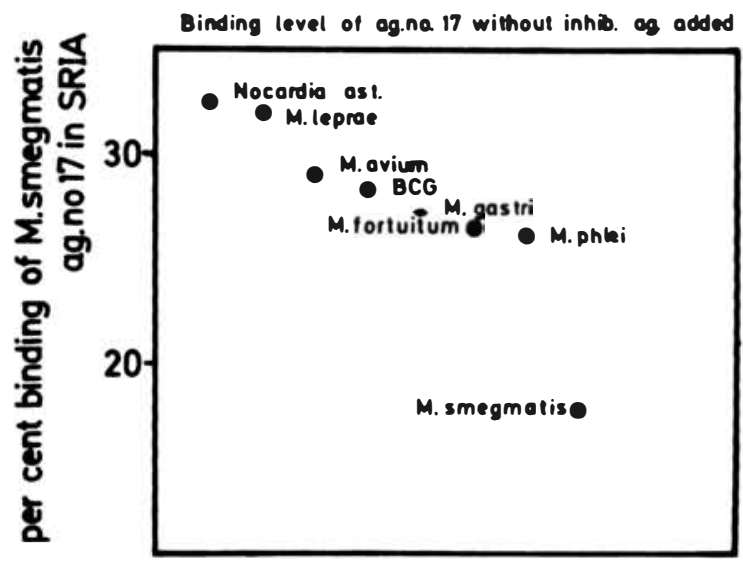

Fig. 2. Inhibition of the binding of radiolabelled M. smegmatis antigen No. $\overline{17}$ by antigen extracts of mycobacteria in a staphylococcal radioimmunoassay. Rabbit anti-M. smegmatis was used as the $\overline{\text { antibody }}$ source. Mycobacterial species tested in the inhibition assay are indicated in the figure.

Species specific determinants of this kind might constitute the basis for a M. leprae specific radioimmunoassay which has been developed (24). The sensitivity of the test was 98.48 in a lepromatous group, $100 \%$ in borderline patients, and $41.7 \%$ among tuberculoid patients. The specificity as tested in a non-endemic area was $100 \%$, but decreased to $89.5 \%$ in a small group of people in an ende- 
mic area. Further studies might indicate the possible use of this promising test.

Several methods developed during the last decade for the de,termination of cellular immune responses have been applied to studies in leprosy. Early studies showed a good correlation with resistance and with the corresponding clinical spectrum (25). Further investigations have indicated a more complex situation with great variations, depending on heterogeneity of the antigenic specificity in individual patients and of the cell populations involved $(26,27,28)$. These methods, particularly LTT and LMTT, have provided new insight into immunological events in leprosy.

Further applications of tests for cell mediated immunity to studies of contacts of leprosy patients have revealed information of great epidemiological and theoretical importance $(29,30,31)$. These studies indicated that exposure to leprosy bacilli is far more widespread than previously known. They also showed a great potential of these methods for use in epidemiological studies. Extensions to field conditions revealed increased responses in contacts of lepromatous patients and confirmed the value of using immunological tests

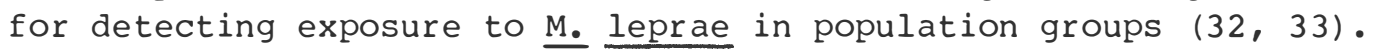

Far from being forgotten, the classical skin test has received continued interest. Previous studies using lepromin have been reviewed (34). Recent investigations have focused on this test as a tool in epidemiological studies using different antigen preparations. Sonicated extracts called "new tuberculins" have been employed for studies of crossreactivity between mycobacterial species and for studies of environmental sensitization (35). A skin test indicating low resistance to the leprosy bacillus has also been described (36).

The impressive achievements in leprosy research in recent years as reviewed in part above seem to be the result of two factors: new immunological techniques and availability of armadillo-grown $\mathrm{M}$. leprae. A comparison with developments in studies of tuberculosis shows, however, that in both fields the test methods developed fall short of requirements for a more widespread use in clinical and epidemiological practise. The main defect is in terms of specificity of the tests. The immunological methodology available today gives a very high sensitivity. The specificity, on the other hand, is dependent on the antigens used.

Mycobacterial antigens in immunological tests

The performance of immunological tests depends critically on the quality of the antigens used. Antigens related to the bacterial cell surface deserve special attention in this connection. Such antigens have been utilized in several assays. A diagnostic test in tuberculosis with high specificity was based on agglutination of whole bacilli (6), the FLA-ABS test detects antibodies directed against surface antigens of M. leprae (17). Whole M. leprae bacilli show better species specificity in tests for cell mediated immunity 
(LTT) than other preparations (32). Eearlier studies also point to cell wall associated antigens as components of considerable interest. Species specific determinants were detected on the surface of mycobacteria independently by Wilson and Griffith already in 1925 . Several decades of work by Schaefer has clearly established that surface antigens carry determinants which permit not only species identification but also intra-species typing (37).

One defined mycobacterial antigen is of special interest in relation to cell wall associated components, M. leprae antigen No. 7 and the corresponding BCG antigen No. 60. This antigen constitutes the main component of PPD preparations and also of sonicated cell wall preparations (38). The type of precipitin line seen with this antigen in crossed immunoelectrophoresis is very characteristic with a fairly broad precipitate extending from the antigen well. Similar precipitates can be seen in crossed immunoelectrophoresis of staphylococcus aureus (39), Neisseria meningitidis (40), and Pseudomonas aeruginosa (41) and represent cell wall components from these species. No well defined precipitin line is obtained due to its heterogeneity.

The basis for the heterogeneity is illustrated in fig. 3. The bacterial cell surface carries various antigen components such as protein and carbohydrates linked covalently to the mucopeptide (fig. 3A). Disruption of bacterial cells for the release of soluble antigens is a fairly random and incomplete procedure with fragments of very different sizes. Soluble cell wall fragments are of high molecular weight and show a very typical feature in the fact that individual molecules might carry several different surface components (fig. 3B) .

The situation leads to difficulties in purification procedures as can be exemplified with results from studies of another bacterial species, a group G streptococcal strain, carrying surface receptors for immunoglobulin $G$ as well as for albumin. These two receptors are different protein molecules bound to the bacterial cell surface. When a sonicate of this strain was subjected to affinity chromatography on an albumin column, not only the albumin receptor was bound but also 36\% of the immunoglobulin receptor, apparantly due to its molecular linkage to the same cell wall fragments as the former (Kronvall G, Wernbro L, 1980). It is therefore difficult to obtain surface antigens in pure preparations using conventional methods. Because of the apparent importance of these antigens, new methods for their isolation are urgently needed. 


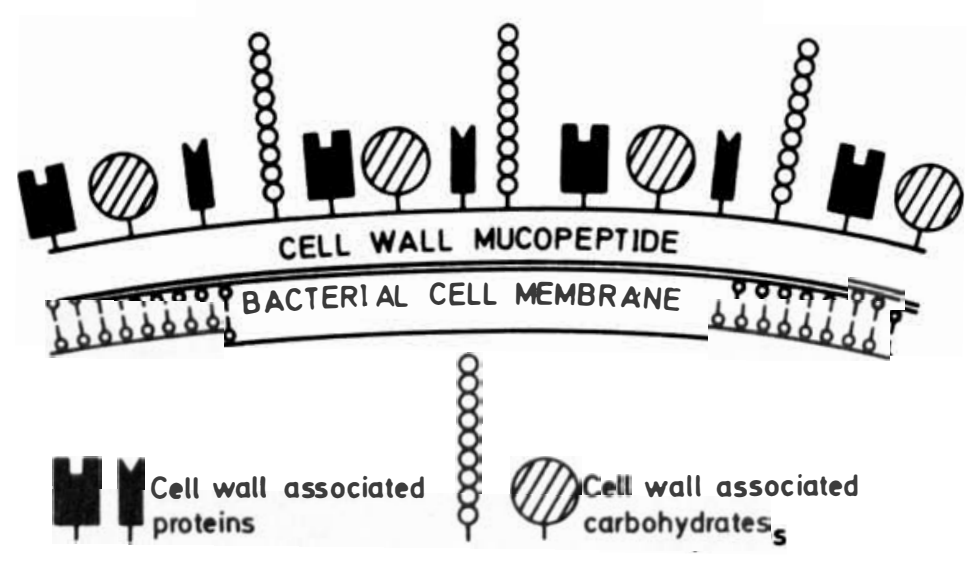

Fig. 3A. Schematic drawing of a bacterial cell wall and its associated components showing features common to many species.

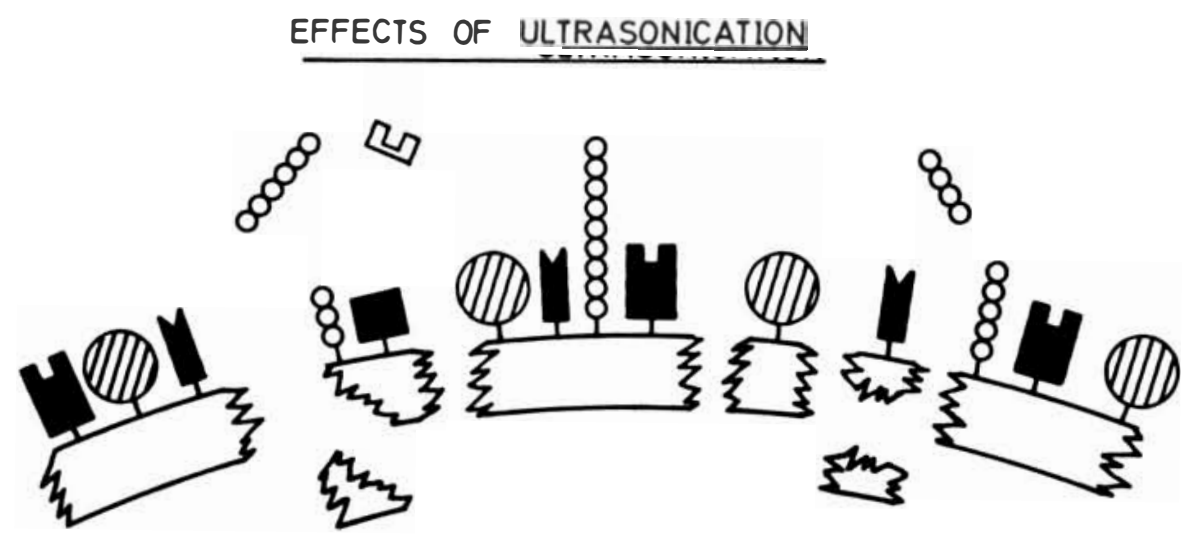

Fig. 3B. Disruption of bacterial cell walls gives rise to soluble fragments carrying different sets of cell wall associated antigens.

\section{Summary}

A review of some previous applications of immunological tests in leprosy and for comparative purposes also in tuberculosis has shown that specificity of the tests constitutes the major constraint on 
their use on a larger scale for epidemiological purposes. The main factor of importance for specificity is the quality of the antigen used in the test. As cell surface antigens seem particularly promising in terms of specificity, a better definition and separation or these components might open new avenues for continued progress in the field of leprosy research.

\section{$\underline{\text { References }}$}

1 Vecchio TJ. Predictive value of a single diagnostic test in unselected populations. N Engl J Med, 1966, 274, 1171-1173.

2 Middlebrook G, Dubos RJ. Specific serum agglutination of erythrocytes sensitized with extracts of tubercle bacilli. J Exp Med, 1948, 88, 521-528.

3 Boyden SV, Sorkin E. A study of antigens active in the tannic acid hemagglutination test present in filtrates of culture of Mycobacterium tuberculusis. J Immunol, 1955, 75, 15-21.

4 Parlett RC. The present status of the sero-diagnosis of tuberculosis. Committee on bacteriology and immunology. Bull Int Un Tuberc, $1964,34,9-35$.

5 Froman S, Burge R, Gedebou M, Picklett MJ. Serologic testing for tuberculosis. Am Rev Resp Dis, 1968, 97, 201-205.

6 Nicholls AC, Horsfie $\overline{l d ~ K . ~ S e r o l o g i c a l ~ d i a g n o s i s ~ o f ~ t u b e r c u l o s i s: ~}$ a report of 12 month's clinical experience. Thorax, 1976, 31, 289-293.

7 Minden P, Farr RS. Binding between components of the tubercle bacillus and humoral antibodies. J Exp Med, 1969, 130, 931954.

8 Nassau E, Parsons ER, Johnson GD. Detection of antibodies to Mycobacterium tuberculosis by solid phase radioimmunoassay. J Immunol Meth, 1975, 6, 261-271.

9 Kronvall G, Bjune G, Stañford J, Menzel S, Samuel D. Mycobacterial antigens in antibody responses of leprosy patients. Int J Lepr, 1975, 43, 299-306.

10 Youmans GP. Relation between delayed hypersensitivity and immunity in tuberculosis. Am Rev Resp Dis, 1975, 111, 109-118.

11 Bergman R. In vitro assays of cell-mediated immunity in calves with persistent Mycobacterium avium infections do not correlate with delayed skin hypersensitivity. Vet Immunol Immunopath, 1980, 1, 387-399.

12 Bjune G. Significance of immune reactions in leprosy. J Oslo City Hosp, 1980, 30, 81-100.

13 Norlin M, Navalkar $\overrightarrow{R G}$, Ouchterlony Ö, Lind A. Characterization of leprosy sera with various mycobacterial antigens using double diffusion-in-gel analysis - III. Acta path microbiol scandinav, 1966, 67, 555-562.

14 Axelsen, $\mathrm{NH}$, Harboe $\bar{M}$. Closs 0 . Godal T. BCG antibody profiles in tuberculoid and lepromatous leprosy. Infect Immun, 1974, 9, 952-958. 
15 Harboe M, Closs (), Bjorvatn B. Bjune G. Antibodies against BCG antigen 60 in mycobacterial infection. Brit Med J, 1977, 2 , $430-433$.

16 Abe M. Studies on the antigenic specificity of Mycobacterium leprae. I. Demonstration of soluble antigens in leprosy nodules by immunodiffusion. Int J Lepr, 1970, 38, 113-125.

17 Abe M, Minagawa F, Yoshino Y, Ozawa T, Saikawa K, Saito T. Fluorescent leprosy antibody absorption (FLA-ABS) test for detecting subclinical infection with Mycobacterium leprae. Int J Lepr, 1980, 48, 109-119.

18 Kronvall G, Stanford J, Walsh GP. Studies of mycobacterial antigens, with special reference to Mycobacterium leprae. Inf Immun, 1976, 13, 1132-1138.

19 Harboe M. Closs 0, Bjorvatn B, Kronvall G, Axelsen NH. Antibody response in rabbit to immunization with Mycobacterium leprae. Inf Immun, 1977, 18, 792-805.

20 Closs 0, Mshana RN, Harboe $\bar{M}$. Antigenic analysis of Mycobacterium leprae. Scand J Immunol, 1979, 9, 297-302.

21 Harboe M. Closs O, Rees RJW, Walsh GP. Formation of antibody against Mycobacterium leprae antigen 7 in armadillos. J Med Microbiol, 1978, 11, 525-535.

22 Kronvall G, Closs 0, Bjune G. Common antigen of Mycobacterium leprae, M. lepraemurium, M. avium, and M. fortuitum in comparative studies using Ewo different Eypes of antisera. Inf Immun, 1977, 16, 542-546.

23 Widebäck K, Kronval $\bar{l}$ G, Bjorvatn B, Closs 0, Harboe M. Comparative studies of antigen 21 in Mycobacterium and Nocardia species: Possible taxonomic re $\overline{\text { lationships with Mycobacterium }}$ leprae. Infect Immun, 1980, 30, 413-420.

24 Harboe M, Closs O, Bjune G, Kronvall G, Axelsen NH. Mycobacterium leprae specific antibodies detected by radioimmunoassay. Scand J Immunol, 1978, 7, 111-120.

25 Godal T. Immunological Aspects of Leprosy - Present Status Progr. Allergy, 1978, 25, 211-242.

26 Bjune G. Barnetson RStC, Ridley DS, Kronvall G. Lymphocyte transformation test in leprosy; correlation of the response with inflammation of lesions. Clin Exp Immunol, 1976, 25, 85-94.

27 Bjune G. Comparison of various preparations of Mycobacterium leprae and other mycobacteria by lymphocyte stimulation. Int JLepr, 1978, 46, 386-393.

28 Bjune G. Variation of in vitro lymphocyte responses to M. leprae antigen in borderline tuberculoid leprosy patients. Int J Lepr, 1980, 48, 30-40.

29 Godal T, Löfgren M, Negassi K. Immune response to M. leprae of healty leprosy contacts. Int J Lepr, 1972, 40, $2 \overline{43}-\overline{250}$.

30 Godal T, Negassi K. Subclinical infection in leprosy. Brit Med J, $1973, \underline{3}, 557-559$.

31 Myrvang B, Negassi K, Löfgren M, Godal T. Immune responsiveness to Mycobacterium leprae of healthy humans. Comparison between leucocyte migration inhibition, lymphocyte transformation, 
and skin testing. Acta path microbiol scand Sect C, 1975, 83, 43-51.

32 Menzel S, Bjune G, Kronvall G. Lymphocyte transformation test in healthy contacts of patients with leprosy. I. Influence of exposure to leprosy within a household. Int J Lepr, 1979, 47 , $138-152$.

33 Menzel S, Bjune G, Kronvall G. Lymphocyte transformation test in healthycontacts of patients with leprosy. II. Influence of consanguinity with the patient, sex and age. Int J Lepr, 1979, 47, 153-160.

34 Newell KW. An epidemiologist's view of leprosy. Bull WId HIth Org, 1966, 34, 827-857.

35 Stanford JL, Shield MJ, Rook GAW. Mycobacterium leprae, other mycobacteria and a possible vaccine. In Latapi F, Saul A, Rodriguez 0, Malacara M, Browne SG, eds. Leprosy. Amsterdam Oxford - Princeton: Excerpta Medica, 1980, 102-107.

36 Convit J, Avila JL, Goihman M, Pinardi ME. A test for the determination of competency in clearing bacilli in leprosy patients. Bull Wld Hlth Org, 1972, 46, 821-826.

37 Schaefer WB. Serologic identification and classification of the atypical mycobacteria by their agglutination. Am Rev Respir Dis, 1965, 92, (Suppl.), 85-93.

38 Closs 0 , Harboe $M$, Axelsen NH, Bunck-Christensen K, Magnusson M. The antigens of Mycobacterium bovis, strain BCG, studied by crossed immunoelectrophoresis: a reference system. Scand J Immunol, 1980, 12, 249-263.

39 Espersen F, Schiötz PO. Normally-occurring precipitating antibodies against Staphylococcus aureus in human serum and colostrum. Acta path microbiol scand, Sect. C, 1981, 89, 93-98.

40 Hoff GE, Höjby N. Cross-reactions between Neisseria meninuitidis and twenty-seven other bacterial species. Acta Path Microbiol scand, Sect. B, 1978, 86, 87-92.

41 Höjby N. Cross-reactions between Pseudomonas aeruginosa and thirty-six other bacterial species. Scand J Immunol, 1975, 4, Suppl. 2, 187-196. 